\title{
Efficacy of oral nifedipine as a tocolytic agent
}

\section{Veena Bikkolli Teekappa Gowda, Madhubala Kalidoss*}

Department of Obstetrics and Gynaecology, KIMS Hospital, Bangalore, Karnataka, India

Received: 25 June 2021

Revised: 22 July 2021

Accepted: 27 July 2021

\section{*Correspondence:}

Dr. Madhubala Kalidoss,

E-mail: madhubala_kalidoss@yahoo.in

Copyright: (C) the author(s), publisher and licensee Medip Academy. This is an open-access article distributed under the terms of the Creative Commons Attribution Non-Commercial License, which permits unrestricted non-commercial use, distribution, and reproduction in any medium, provided the original work is properly cited.

\section{ABSTRACT}

Background: Preterm birth is defined as birth at less than 37 weeks period of gestation, is the most important single determinant of adverse infant outcome in terms of both survival and quality of life. The need for tocolysis in terms of safety and efficacy is necessary to decrease perinatal mortality and morbidity in preterm labour. This study was aimed to evaluate the effectiveness of nifedipine as a tocolytic for inhibiting uterine contraction in threatened preterm labour. Methods: It was a prospective, nonblinded, single centred, randomized control trial. This study included 100 cases of preterm labour admitted in department of obstetrics and gynaecology, KIMSH, Bangalore, who satisfied the inclusion and exclusion criteria and were administered with nifedipine tocolysis.

Results: 100 cases of preterm were evaluated for the prolongation of pregnancy for more than 48 hours. Prolongation of pregnancy till term was observed in $88 \%$ of the cases administered with nifedipine tocolysis. The mean gestational age in each group was $32.58 \pm 1.95$ weeks. Nifedipine had very few side effects, namely tachycardia and headache and no changes in fetal heart rate.

Conclusions: In this study oral nifedipine was found to be efficacious in prolongation of pregnancy for more than 48 hours with the ease of oral administration and with minimal dose tocolytic effect was achieved. It had minimal maternal and neonatal side effects and eliminate the need for intensive maternal monitoring.

Keywords: Nifedipine, Tocolytics, Preterm

\section{INTRODUCTION}

Every year, an estimated 15 million babies are born prematurely and this number is increasing globally. ${ }^{1}$

Preterm birth complications are leading cause of death among children under 5 year of age and it was responsible for nearly 1 million deaths in 2015 worldwide. $^{2}$

Preterm labour remains one of the last frontiers of the present day obstetrics. Prematurity together with its complications remains the most important preventable cause of perinatal mortality and morbidity. The cost of preterm neonatal care is not feasible to all classes of society especially in the developing and underdeveloped countries. Therefore, it is necessary to prevent preterm labour not only in view of cost but also to provide a healthy baby. ${ }^{3}$

The WHO has estimated that 12.9 million births or $9.6 \%$ of all births were preterm in $2005 .^{4}$

Despite the improvement in survival rates of preterm neonates, they are at increased risk of long term neurodevelopmental disabilities and respiratory and gastrointestinal complications.

Uterine contractions are the most frequently recognized symptom and sign of preterm labour, inhibition of uterine contractility with tocolytic agents to prolong pregnancy and reduce neonatal complications continues to be the focus of treatment of preterm labour. ${ }^{5}$ 
Tocolysis means inhibition of uterine contractions by means of pharmacological agents.

In preterm labour, efficacy of tocolytic drugs has been proven to prolong the pregnancy when there is cervical dilatation. $^{6}$

Because of the hazards of the preterm labour such as perinatal morbidity and mortality, effective tocolysis in terms of safety, efficacy and patient compliant is necessitated.

Postponing delivery for 48 hours with tocolysis to allow for maternal steroid administration or antenatal transportation to centre where neonatal intensive care units (NICU) are available is needed in threatened preterm labour. $^{7}$

A wide range of tocolytic agents have been advocated including $\beta$-agonists, calcium channel blockers (CCBs), prostaglandin synthetase inhibitors, magnesium sulphate $\left(\mathrm{MgSO}_{4}\right)$ and oxytocin receptor antagonists. ${ }^{13}$

CCBs are non-specific smooth muscle relaxants, predominantly used for the treatment of hypertension and are increasingly used as a tocolytic agent for women in preterm labour. ${ }^{8}$

CCBs are very effective tocolytic agents in preterm labour and has comparatively lesser side effects than betamimetics.

Dihydropyridine CCBs, like nifedipine and nicardipine, act on L-type calcium channels to inhibit calcium influx into myometrial cells. Reduced intracellular calcium concentrations prevent activation of myosin light chain kinase and thereby myometrium contraction. ${ }^{9}$

Nifedipine is an effective smooth muscle relaxant with low toxicity and no teratogenicity. It may represent an attractive therapeutic alternative due to its relaxing effects on myometrium.

It has gained popularity as a tocolytic due to its oral route of administration, availability of immediate and slowrelease preparations and low incidence of maternal adverse effects

Nifedipine is considered as one of the first-line tocolytic agent for the management of preterm labour with the standard dosage of 10-20 mg every 3-6 hours. ${ }^{1}$

Adverse events associated with nifedipine are usually mild and related to peripheral vasodilation, like flushing. In normotensive women with no underlying heart disease, there is typically minimal effect on blood pressure due to a compensatory rise in heart rate and stroke volume. ${ }^{9}$
Other adverse events, most of which occur rarely and in women with other risk factors include pulmonary oedema, dyspnoea and myocardial infarction.

Nifedipine in comparison to the other tocolytics has been effective in significant reduction in admission of newborns to NICU and associated with lower incidence of respiratory distress syndrome as preterm labour possess a huge economic burden to the society. ${ }^{10}$

Nifedipine is the most commonly studied CCB and several meta-analyses support its effectiveness for acute tocolysis. ${ }^{9}$

And therefore, this study was undertaken to prove the efficacy of nifedipine, a calcium channel antagonist in the treatment of preterm labour.

\section{METHODS}

This study consisted of 100 randomized patients admitted with a diagnosis of preterm labor in the department of obstetrics and gynaecology from Kempegowda institute of medical sciences and research centre, Bangalore.

It was a prospective, non-blinded, single centered randomized control study for a period of two years from January 2017 to June 2019. Total 2700 patients delivered from January 2017 to 2019, out of which 388 were preterm patients. Total 100 patients who satisfied the inclusion and exclusion criteria were taken into the study. An informed and written consent was taken from all the subjects.

The statistical analysis was performed by STATA 11.2 (College Station TX USA). Chi square test for goodness of fit were used to measure the association between the age distribution, booked/unbooked, parity, previous history of PTD, prolongation of pregnancy in days, cause of preterm, maternal side effects, prolongation of pregnancy till term and fetal tachycardia with nifedipine treatment and these were expressed as frequency and percentage. Students independent sample $t$ test were used to measure the significance difference between the age, period of gestation with treatment groups and these expressed as mean and standard deviation. $\mathrm{P}<0.05$ is considered as statistically significant.

\section{Inclusion criteria}

Patients with singleton pregnancy in cephalic presentation with gestational age between 28-36 weeks, patients with uterine contractions four in $20 \mathrm{~min}$ or eight in $60 \mathrm{~min}$ lasting for 30 seconds or more, patients with cervical dilatation 1 to $3 \mathrm{~cm}$, patients with cervical effacement $80 \%$ or lesser, patients with intact membranes and patients with no previous administration of tocolytics were included in the study. 


\section{Exclusion criteria}

Maternal and fetal indications for termination of pregnancy like medical conditions requiring emergency termination of pregnancy/intrauterine death/lethal fetal anomalies, patients with past medical history of cardiovascular diseases, diabetes mellitus, bronchial asthma, pregnancy induced hypertension, severe anaemia, antepartum haemorrhage, patients with multiple pregnancy and malpresentation, patients with uterine malformations and patients where the cervical dilation was $>4 \mathrm{~cm}$ was excluded from the study.

Detailed complete history was taken regarding age, occupation, socioeconomic status and any history of infections, obstetric history and history of previous preterm deliveries, abortions and history of co-morbidities. Cases were monitored by clinical signs and symptoms, maternal pulse and blood pressure, uterine contractions, BP charting, non-stress test. Relevant investigations including high vaginal swabs and CRP, ESR were sent. The frequency and duration of uterine contractions were monitored clinically by manual palpation.

\section{Drug dosage}

100 patients received oral nifedipine. A loading dose of 20 $\mathrm{mg}$ initially followed by $10-20 \mathrm{mg}$ three to four times daily adjusted according to the uterine activity for up to 48 hours. All the patients received injection betamethasone 12 mg 2 doses 24 hours apart.

\section{RESULTS}

During this study period total number of deliveries that were conducted in the department of obstetrics and gynaecology were around 2700 per year out of which 388 cases were diagnosed with preterm labour per year. The incidence of preterm labour was found to be $14.37 \%$ per year. 100 patients who consented for the study were selected.

The study included patients between 19 years to 34 years of age. Majority of the cases belonged to age group between 19-25 years accounting for $56 \%$. The mean age was $24.44 \pm 4.15$. It was observed that most of the cases of preterm were seen in young age group of 19 years to 34 years and reduced incidence of preterm labour in age group between 31-34 years ( 4 cases).

The incidence of preterm labour was found to be more in unbooked cases as when compared to booked cases, where the incidence of preterm labour in booked cases was $36 \%$ and $64 \%$ in unbooked cases. In our study, $50 \%$ of primigravida and $50 \%$ multigravida cases were administered nifedipine tocolysis.

The incidence of preterm labour was found to be maximum between the gestational age of 31-33 weeks accounting to
$46 \%$, followed by $34-36$ weeks which was $38 \%$ weeks and $16 \%$ were between $28-30$ weeks gestation.

The mean period of gestation was found to be $32.58 \pm 1.95$ weeks in nifedipine administered cases and the range of period of gestation was 29-36 weeks.

Most of the cases who were diagnosed with preterm labour did not have previous history of preterm delivery $(86 \%)$, only $14 \%$ of patients had previous history of preterm delivery. Various etiological factors were responsible for preterm labour and commonest cause of preterm labour was idiopathic cause which was $56 \%$ followed by polyhydramnios, urinary tract infection and lower genital tract infections which were $18 \%, 10 \%$ and $16 \%$ respectively (Figure 1).

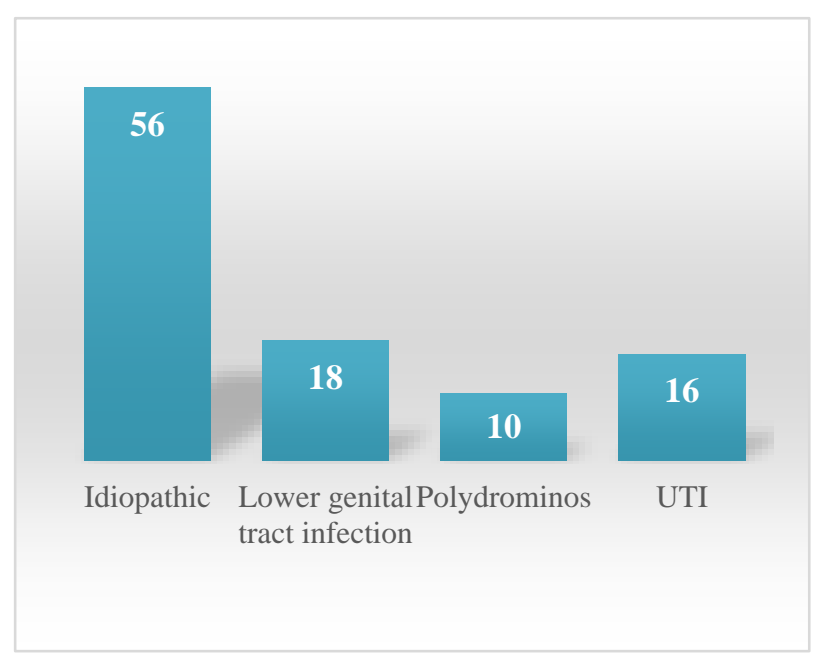

Figure 1: Cause of pre-term.

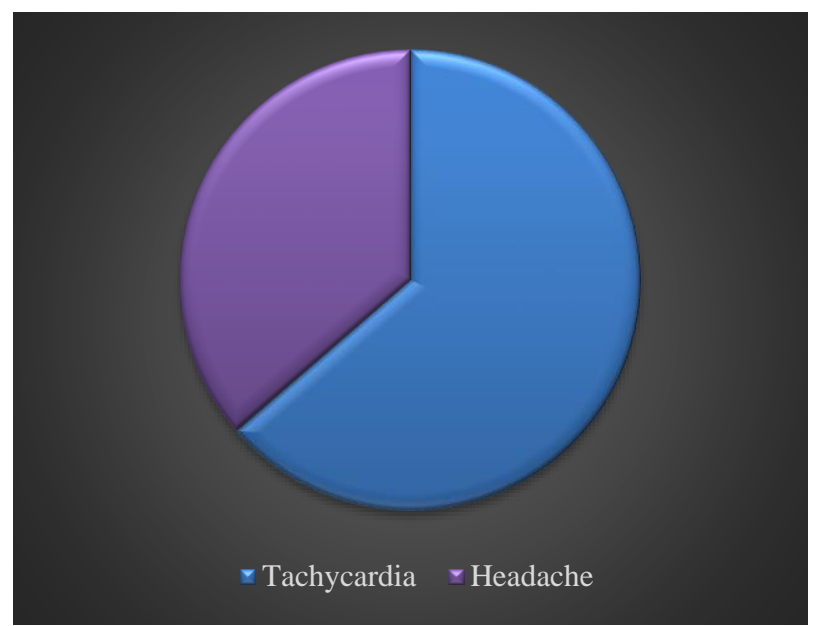

Figure 2: Maternal side effects and fetal side effects.

As our study was to monitor the short term effect of nifedipine, the patients were divided into two categories as in prolongation of pregnancy $<48$ hours and $>48$ hours. The prolongation of pregnancy up to $>48$ hours was $96 \%$ (Table 1). 
Out of 100 cases, $88 \%$ cases had prolongation of pregnancy till term and $6 \%$ of the cases delivered at the gestational age of 32-35 weeks (Table 2).

Various side effects were studied during the study period. The most common side effect noted in nifedipine administration was tachycardia which was about $14 \%$, followed by headache which was $8 \%$. And there was no fetal tachycardia observed in nifedipine administration. (Figure 2).

Table 1: Prolongation of pregnancy in days.

\begin{tabular}{|ll|}
\hline Prolongation (in hours) & Nifedipine (\%) \\
\hline$\leq \mathbf{4 8}$ & $4(4)$ \\
\hline$>\mathbf{4 8}$ & $96(96)$ \\
\hline Total & 100 \\
\hline
\end{tabular}

Table 2: Prolongation of pregnancy.

\begin{tabular}{|l|l|}
\hline Prolongation (in weeks) & Nifedipine (\%) \\
\hline $\mathbf{3 3 7}$ & $88(88)$ \\
\hline $\mathbf{3 5 - 3 7}$ & $5(5)$ \\
\hline $\mathbf{3 2 - 3 5}$ & $6(6)$ \\
\hline $\mathbf{2 8 - 3 2}$ & $1(1)$ \\
\hline
\end{tabular}

\section{DISCUSSION}

Despite of various advances in perinatal medicine preterm birth was one of the major causes of infant morbidity and mortality. Preterm delivery continues to frustrate satisfactory reproductive outcome. Throughout the years a variety of tocolytic agents were used to suppress preterm labour.

The goal of tocolysis is to cause cessation of uterine contractions in patients with preterm labour. Conservative management of the patients with threatened preterm labour with tocolytics will reduce the neonatal morbidity, mortality and the cost of neonatal care.

Beta sympathomimetics agonists are the most commonly used tocolytic agent. However, the incidences of troublesome side effects have led to continuous search for other novel tocolytic agent. Many recent studies have shown that nifedipine is safer, better tolerated, effective with no fetal side effects. Hence this study was undertaken to study the efficacy of nifedipine as a short term tocolytic and to study the side effects of these drugs.

The incidence of preterm labour in our hospital per year was $14.37 \%$. Various studies done worldwide also showed a similar range of incidence. WHO also showed a similar range $5-18 \%$ of incidence of preterm labour.

The primary purpose of tocolytic therapy was to delay preterm labour for 48 hours to allow the maximum benefit of glucocorticoid therapy to decrease the incidence of respiratory distress syndrome by increasing the production of surfactant in the fetal lungs, to prevent neonatal morbidity and mortality.
The most recent substantial update of the Cochrane review regarding $\mathrm{CCBs}$ for acute tocolysis in preterm labour included 12 randomized controlled trials (10 using nifedipine) involving 1029 patients. This review concluded that, when compared with any other tocolytic agent (mainly beta-mimetics), CCBs (mainly nifedipine) reduce the risk of delivery within 7 days of initiation of treatment and delivery before 34 weeks of gestation with improvement in some clinically important neonatal outcomes such as respiratory distress syndrome, intraventricular haemorrhage, necrotizing enterocolitis and neonatal jaundice. ${ }^{11}$

A Cochrane review on CCBs for inhibiting preterm labour showed that nifedipine significantly reduced delivery within seven days of receiving treatment as compared with any other tocolytic agent (relative risk (RR): 0.76 ; $95 \%$ confidence interval (CI): 0.60 to 0.97 ). In addition, as compared to other tocolytics, CCBs also reduced the frequency of neonatal respiratory distress syndrome (RR: 0.63; $95 \%$ CI: 0.46 to 0000.88 ), necrotising enterocolitis (RR: 0.21 ; $95 \% \mathrm{CI}: 0.05$ to 0.96 ), intraventricular haemorrhage (RR: $0.5995 \%$ CI: 0.36 to 0.98 ) and neonatal jaundice (RR: 0.73 ; 95\% CI: 0.57 to 0.93 ) and the requirement for women to have treatment ceased for adverse drug reaction (RR: 0.14 ; $95 \%$ CI: 0.05 to 0.36$){ }^{7}$

A more recent meta-analysis, including 26 studies of 2,179 women, found no difference between nifedipine and other tocolytics in delaying birth at 48 hours. ${ }^{18}$ However, women treated with nifedipine were less likely to deliver within 7 days and more likely to deliver at 37 weeks gestation. ${ }^{9}$

Other studies like Read and Wellby gave an initial loading dose of $30 \mathrm{mg}$ of nifedipine and a maximum maintenance dose of $20 \mathrm{mg}$ every 8 hours for 3 days. Ferguson et al gave an initial maximum loading dose of $40 \mathrm{mg}$ of nifedipine and a maximum maintenance dose of $20 \mathrm{mg}$ every 4-6 hours. ${ }^{4}$ Meyer et al gave an initial loading dose of $30 \mathrm{mg}$ of nifedipine and a maximum maintenance dose of $20 \mathrm{mg}$ every 6 hours. ${ }^{6}$ Kupferminc et al gave an initial loading dose of $30 \mathrm{mg}$ of nifedipine and a maximum maintenance dose of $20 \mathrm{mg}$ every 8 hours. ${ }^{12}$

But in our study, we administered a loading dose of $20 \mathrm{mg}$ initially followed by $10-20 \mathrm{mg}$ three to four times daily adjusted according to the uterine activity for up to 48 hours and achieved good and satisfactory outcomes in terms of prolongation of labour till term and less maternal side effects.

Our study aimed at short term tocolytic effect of nifedipine. Our study showed prolongation of labour $>48$ hours in $96 \%$ of cases which was comparable with other studies such as a study conducted by Bankatlal showed $90 \%$. A study done by Songthamwat showed an incidence of $9.7 \%$ cases which failed to delay prolongation of labour more than 48 hours, where in our study showed an incidence of $4 \%$ of cases who failed to achieve prolongation of labour more than 48 hours. 
In our study $96 \%$ of cases administered with nifedipine remained undelivered for 2 days and prolongation of pregnancy till term was observed in $88 \%$ of cases. Thus, nifedipine was successful in prolongation of pregnancy till term.

Our study showed tachycardia and headache as a predominant side effect of the drug due to its vasodilatory and chronotropic effect. There was no significant fall in blood pressure due to nifedipine.

Our study showed the incidence of palpitations in nifedipine group as $8 \%$, which was similar in various studies conducted by Jaju et al and Cararach et al where the incidence of palpitations was $8 \%$ and $5.1 \%$ respectively. Similarly, the incidence of headache in nifedipine group in our study was $14 \%, 20 \%$ in study conducted by Jaju et al and $4 \%$ in study conducted by Cararach et al. No other significant side effects were observed in nifedipine group. The increase in maternal heart rate was statistically significant when compared to headache.

Fetal heart rate also was monitored during the tocolytic therapy. Nifedipine did not have any effect on fetal heart rate. Similarly various other studies also have showed a similar effect where nifedipine had no effect on fetal heart rate.

\section{Limitations}

This study had a smaller sample size. During the statistical analysis appropriate correction factor was not applied to consider the effect of any possible confounding factors.

\section{CONCLUSION}

Nifedipine in the management of preterm labour is significantly safer and associated with fewer maternal side effects as both short and long term tocolytic agents and there are no fetal side effects. It reduces the need for continuous intensive maternal monitoring as required in other tocolytics. Nifedipine had the ease of oral administration and with minimal dosage the tocolytic effect was accomplished and the pregnancy was carried till term.

Hence, we recommend the use of oral nifedipine as it is safer and efficacious for management of preterm labour.

Funding: No funding sources

Conflict of interest: None declared

Ethical approval: The study was approved by the Institutional Ethics Committee

\section{REFERENCES}

1. Songthamwat $\mathrm{S}$, Nan $\mathrm{CN}$, Songthamwat $\mathrm{M}$. Effectiveness of nifedipine in threatened preterm labor: a randomized trial. Int J Womens Health. 2018;10:31723.

2. Liu L, Oza S, Hogan D, Perin J, Rudan I, Lawn JE, et al. Global, regional, and national causes of child mortality in 2000-13, with projections to inform post-2015 priorities: an updated systematic analysis. Lancet. 2015;385(9966):430-40.

3. Jaju PB, Dhabadi B. Nifedipine vs Ritodrine for suppression of preterm laor. J Obstet Gynaecol India. 2011;61(5):534-7.

4. Beck S, Wojdyla D, Say L, Betran AP, Merialdi M, Requejo JH, et al. The worldwide incidence of preterm birth: a systematic review of maternal mortality and morbidity. Bull World Health Organ. 2010;88(1):31-8.

5. Conde-Agudelo A, Romero R, Kusanovic JP. Nifedipine in the management of preterm labor: a systematic review and meta-analysis. Am J Obstet Gynecol. 2011;204(2):134.

6. Pawar P, Pawar A. Nifedipine versus isoxsuprine for suppression of preterm labour-a comparative randomised study. 2020;9(9):384-91.

7. Vliet EOV, Schuit E, Heida KY, Opmeer BC, Kok M, Gyselaers W, et al. Nifedipine versus atosiban in the treatment of threatened preterm labour (assessment of perinatal outcome after specific tocolysis in early labour: APOSTEL III-trial). BMC Pregnancy Childbirth. 2014;14:93.

8. Hangekar PM, Karale A, Risbud N. Our experience of nifedipine as a tocolytic agent in preterm labor (24 weeks to 36 weeks 6 days). Int J Reprod Contracept Obstet Gynecol. 2017;6(2):636-9.

9. Haas D, Benjamin T, Sawyer R, Quinney S. Short-term tocolytics for preterm delivery-current perspectives. Int J Womens Health. 2014;6:343-9.

10. Adegoke AS, Fasuba OB. Comparing the effectiveness of two different dosage regimens of oral nifedipine in the treatment of preterm labour. Trop J Obstet Gynaecol. 2020;37(1):67-71.

11. King JF, Flenady VJ, Papatsonis DN, Dekker GA, Carbonne B. Calcium channel blockers for inhibiting preterm labour. Cochrane Database Syst Rev. 2003;(1):002255.

12. Papatsonis DNM, Geijn HPV, Adèr HJ, Lange FM, Bleker OP, Dekker GA. Nifedipine and ritodrine in the management of preterm labor: a randomized multicenter trial. Obstet Gynecol. 1997;90(2):230-4.

13. Nassar AH, Abu-Musa AA, Awwad J, Khalil A, Tabbara J, Usta IM. Two dose regimens of nifedipine for management of preterm labor: a randomized controlled trial. Am J Perinatol. 2009;26(8):575-81.

Cite this article as: Gowda VBT, Kalidoss M. Efficacy of oral nifedipine as a tocolytic agent. Int J Reprod Contracept Obstet Gynecol 2021;10:3450-4. 